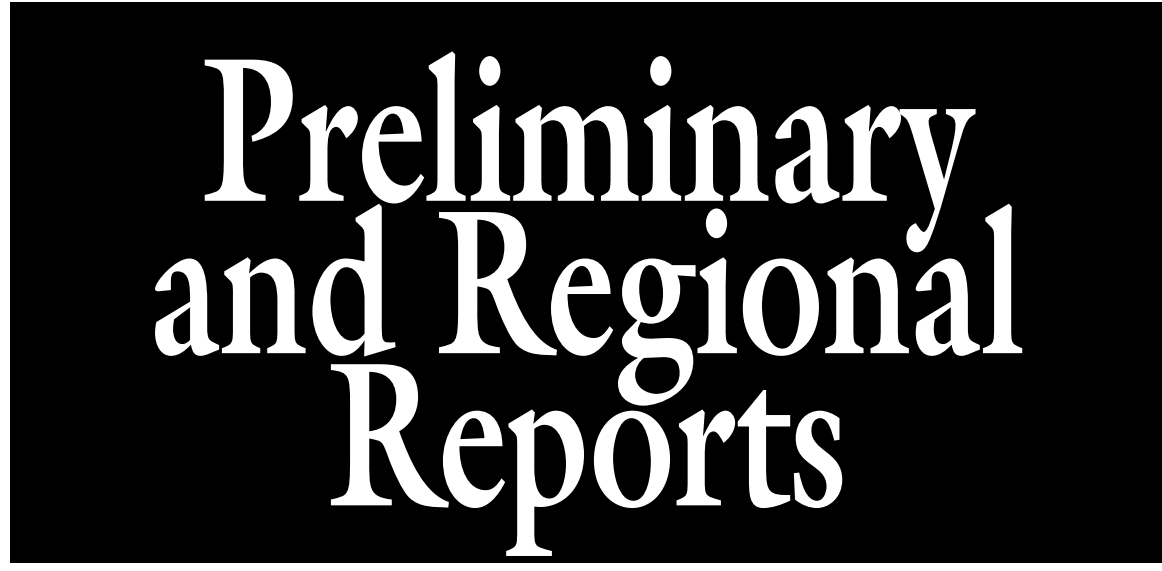

\section{Exploring Produce Industry Attitudes: Relationships between Postharvest Handling, Fruit Flavor, and Consumer Purchasing}

\author{
David C. Diehl ${ }^{1,5}$, Nicole L. Sloan ${ }^{1}$, Christine M. Bruhn ${ }^{2}$, \\ Amarat H. Simonne ${ }^{1}$, Jeffrey K. Brecht ${ }^{3}$, and Elizabeth J. Mitcham ${ }^{4}$
}

ADDITIONAL INDEX WORDs. interviews, maturity, quality, retail, supply chain, temperature, transportation

Summary. As part of a larger project to show how fresh fruits and vegetables with enhanced flavor can be successfully handled to improve consumer satisfaction without compromising food safety, key informant interviews were conducted with fruit industry leaders dealing with melons (Cucumis melo and Citrullus lanatus), peaches and nectarines (Prunus persica), pears (Pyrus communis), tomatoes (Solanum lycopersicum), strawberries (Fragaria $\times$ ananassa), and blueberries (Vaccinium sp.). The interview was designed to collect information on industry attitudes and practices related to postharvest handling of more mature fruit, harvest timing, preconditioning, cold chain management, and shipping and handling procedures throughout the supply chain. The current analysis focuses on two key questions from the interviews: 1) To what extent do industry experts believe that better fruit handling and shipping procedures contribute to better taste quality in fruit? 2) To what extent do industry experts believe that better fruit quality will lead to more consumer purchasing? In response to the first question, the majority of respondents $(70 \%)$ agreed that postharvest handling affects fruit flavor with the most cited themes related to agreement being gentle handling, cold chain management, and harvest timing. Of the respondents who expressed disagreement most acknowledged the importance of postharvest handling, but felt other factors were also important, mainly the variety grown, the shelf life requirements, and the growing conditions. For the second question, $95 \%$ of respondents agreed that increased taste quality of fruit would mean increased purchasing and consumption. The primary theme related to agreement was that consumers would repeat purchase after positive eating experiences. Other important factors were the price point of fruit, retail display, product identity, and fruit appearance. With increasing consumer attention to fruit quality and a generally accepted belief among industry representatives that fruit flavor and quality drives consumer demand, there is an opportunity to shift industry practices toward postharvest handing that is conducive to consistently delivering better-tasting fruit to consumers.

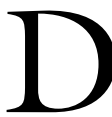
espite the numerous health benefits of fruit consumption, recent research has found that less than $10 \%$ of Americans meet the recommended daily guidelines for fruit intake (Kimmons et al., 2009). From
2000 to 2009 , the percentage of Amerper day actually decreased (Centers for Disease Control and Prevention, 2010). being made to encourage consumption icans consuming fruit at least two times At the federal level, a renewed effort is of produce, with the core message of making half your plate fruits and vegetables (Post et al., 2011). From the perspective of the fruit industry, increased consumption represents an opportunity to contribute not only to the health and well-being of Americans, but also to the competitiveness and profits of the industry.

Kader (2008) proposed that better fruit flavor is an important factor in shaping how much fruit is being consumed and emphasized both preharvest and postharvest variables that influence fruit quality. The essential challenge of providing consumers with high-quality, flavorful fruit is that more mature or riper fruit is softer, is more prone to injury during harvesting and transporting, and has a shorter shelf life. Therefore, maintaining flavor quality requires attention to a variety of factors, including harvest timing, cold chain management, time to market, modified atmospheres (MAs), and shipping and handling practices throughout the supply chain (Beckles, 2012; Brecht et al., 2003; Cantwell et al., 2009; Toivonen, 2007).

Although most growers prefer to provide consumers with a positive eating experience, many make a business decision to choose shipability and shelf life over fruit quality and taste. This decision shapes their variety selection and harvest scheduling, both of which can compromise fruit quality and flavor (Tijskens et al., 2007); current practices, including an emphasis on long shelf life, nonoptimal harvest maturity, and improper storage temperatures, are not compatible with optimal fruit quality and consumer satisfaction (Mitcham, 2010).

For some experts, harvest timing, as it influences flavor development, is seen as the strongest determiner of fruit quality because harvest interrupts the production of sugars, while processes such as transpiration and respiration continue (Zerbini, 2008). Growers who supply fruit harvested at optimum maturity must "identify optimal postharvest handling conditions" to preserve fruit flavor (Kader, 2008) and need to understand how postharvest handling conditions affect the flavor life of specific types of fruit (Forney, 2001). Consumer preferences for quality take into account several factors, including fruit appearance, texture, and flavor (Kader, 2000), with the effect of fruit quality on 
consumption being evidenced by whether the consumer repeats buying (Mitcham, 2010). Although consumers frequently purchase fruit based on physical appearance and texture, repeat buying is dependent upon consumer satisfaction with fruit flavor (Kader, 2001), which is a strong argument for basing postharvest life on flavor and not appearance (Kader, 2008). In the case of tomatoes, Beckles (2012) stated that the eating experience "depends on several highly interacting factors, genetic-, agronomic-, climactic- and various postharvest handling-related issues." Because these factors are relevant to all fruit, the industry must balance the interests of flavor with the realities of the supply chain in an effort to deliver the highest-quality produce.

Although there is considerable research on the benefits of good postharvest fruit handling practices, there is little social science research on the attitudes and practices of the produce industry in the arena of postharvest handling. This research draws on key informant interviews with fruit industry leaders designed to collect information on their attitudes and practices related to postharvest handling of more mature or riper fruit, harvest timing, preconditioning, cold chain management, shipping and handling procedures, and supply chain management. This research was conducted as part of a larger project, which was a joint effort of the University of California, Davis, and the University of Florida funded by the U.S. Department of Agriculture, National Institute of Food and Agriculture. The project, titled "Increasing Consumption of Specialty Crops by Enhancing their Quality and Safety," had the overall goal of demonstrating how fresh fruits and vegetables with enhanced flavor can be successfully handled,

\footnotetext{
This project was supported by a Specialty Crops Research Initiative Grant (2009-51181-05783) from the USDA National Institute of Food and Agriculture.

We thank Steven Sargent and Allen Wysocki for their review of this manuscript.

${ }^{1}$ Department of Family, Youth and Community Sciences, University of Florida, Gainesville, FL 32611

${ }^{2}$ Food Science and Technology Department, University of California, Davis, CA 95616

${ }^{3}$ Horticultural Sciences Department, University of Florida, Gainesville, FL 32611

${ }^{4}$ Department of Plant Sciences, Postharvest Technology Center, University of California, Davis, CA 95616

${ }^{5}$ Corresponding author. E-mail: dcdiehl@ufl.edu.
}

without compromising food safety, so as to improve consumer satisfaction and thereby change their buying habits to increase consumption. The project addressed all segments of the supply chain and focused on melons, pears, peaches, nectarines, tomatoes, strawberries, and blueberries. Although tomato is commonly categorized as a vegetable by consumers and the horticulture industry, it is botanically a fruit. Thus, we have chosen to collectively refer to all of the produce items in this study as "fruit."

The objective of this article is to use qualitative methods to explore the extent to which fruit industry experts believe that postharvest fruit handling affects fruit flavor and the extent to which these experts believe that improved taste quality would lead to increased consumer purchasing.

\section{Methods}

A detailed interview protocol, approved by the Institutional Review Boards of the University of California, Davis, and the University of Florida, was developed and piloted in collaboration with project experts and key industry representatives. Because of logistical constraints and practical concerns related to obtaining time commitments from busy professionals, a convenience sample was used. The interviewees were largely drawn from existing networks of contacts and project stakeholders who were considered to be more likely to participate in the interview process. Key informant interviews lasting $\approx 45-60 \mathrm{~min}$ were conducted via phone with 37 industry representatives who were growers, packer/shippers, retailers, or produce industry association staff members dealing with the relevant fruit.

Consistent with the objectives and approaches of the broader project, the interviewees represented predominantly large growers, packer/ shippers, and retailers. Grower production ranged from a low of 30,000 cartons to a high of 13 million cartons of fruit annually and retailer gross produce sales ranged from $\$ 92$ million to $\$ 1$ billion annually. The growers and packer/shippers were drawn from locations most likely to produce the fruit of interest and many of them produced in multiple locations. All companies had domestic growing operations representing 14 states, with 15 in California, 12 in Florida, and 3 each in Alabama, Georgia, and Virginia. Twenty of these companies also had international growing operations, with seven in Central America, six in Mexico, four in South America, and two in Canada. The retailers were primarily regional and national with almost all serving several states.

The interviewees were defined as "key decision makers" in their organizations, meaning they had the capacity and power to make decisions related to postharvest handling practices. Typical job titles include the following: senior crop manager, vice president of quality control for produce, regional manager of quality control, director of quality control, senior director of sales and product management, vice president of technical operations, president and chief executive officer, and owner/operator. These interviewees were categorized according to their industrial role, with "growers" being combined with "grower/packer/ shippers" because there were only three growers who did not also pack and ship fruit. The "other" category includes individuals such as seed company representatives who did not fit in any other category (Table 1 ).

The interviews were broader than the topics presented in this research and included challenges and solutions related to getting better-tasting fruit to consumers, price and quality issues in the fruit supply chain, leverage and power in the fruit supply chain, and current industry capacity and desire for additional support. The current analysis focuses on two key questions related to the logical propositions put forth by the project: 1) To what extent do industry experts believe that better fruit handling and shipping procedures contribute to better taste quality in fruit? 2) To what extent do industry experts believe that better fruit quality will lead to more consumer purchasing?

\begin{tabular}{llll}
\hline $\begin{array}{l}\text { Units } \\
\text { To convert U.S. to SI, } \\
\text { multiply by }\end{array}$ & U.S. unit & SI unit & $\begin{array}{l}\text { To convert SI to U.S., } \\
\text { multiply by }\end{array}$ \\
\hline$\left({ }^{\circ} \mathrm{F}-32\right) \div 1.8$ & ${ }^{\circ} \mathrm{F}$ & ${ }^{\circ} \mathrm{C}$ & $\left({ }^{\circ} \mathrm{C} \times 1.8\right)+32$
\end{tabular}

Horllednology October $201323(5)$ 
To address the first logical proposition, the following question prompt was used: If better fruit handling and shipping procedures were used, such as better packaging and better temperature control, how confident are you that there would be a significant increase in taste quality for fruit? For the second proposition, the following prompt was used: If the taste quality of fruit was increased significantly, how confident are you that consumers would purchase more of each kind of fruit?

The interviews were recorded and transcribed for analysis. These data were coded and analyzed using XSight qualitative analysis software (version 2; QSR International, Melbourne, Australia). The research team developed the qualitative coding scheme using an inductive approach (Thomas, 2006), which identified major categories based on repeated reading, analysis, and discussion of the transcripts. The first level of analysis was to assign a code representing each interviewee's degree of agreement with the logical propositions: "strongly agree," "mostly agree," "mostly disagree," and "strongly disagree." For each individual, the research team determined whether the interviewee generally agreed with or disagreed with the logical proposition. The team then used the strength of interviewee language to arrive at the finer distinction between "strongly" and "mostly" agreeing or disagreeing. For example, a respondent who said he "absolutely" or "100\%" agreed would be categorized as "strongly agree."

The second level of analysis categorized the themes related to agreement and themes related to disagreement pertaining to the logical propositions. Themes related to agreement tended to be relatively straightforward, whereas themes related to disagreement tended to be more complicated. Themes related to disagreement might include clear statements of disagreement as well as alternative considerations or qualifiers to agreement. Many respondents expressed qualified agreement for a proposition, for example, when asked about the strength of the relationship between fruit handling and fruit flavor, one individual said, "I think it is part of the equation. I think good genetics are a piece of this as well." In this case, genetics would be identified as an alternative consideration important to fruit flavor and quality. For the sake of simple presentation, such alternative considerations and themes related to disagreement are grouped together and presented under the heading of "themes related to disagreement" for the rest of this article.

For both levels of analysis, the research team arrived at consensus on all code labels and code assignments.

\section{Results and discussion Logic l: Relationship between fruit handling and fruit flavor}

The first question for this study was to what extent do industry decision makers agree with the proposition that better postharvest fruit handling is related to better fruit flavor? Interviewees were asked, "If better fruit handling and shipping procedures were used, such as better packaging and better temperature control, how confident are you that there would be a significant increase in taste quality for fruit?"

The qualitative analyses revealed that, on balance, industry decision makers agree with the proposition that postharvest fruit handling is critical to maintaining good fruit flavor. Twenty-six of the respondents $(70 \%)$ were categorized as agreeing with this proposition, with 18 of these strongly agreeing (49\%) and 8 mostly agreeing $(22 \%)$. Eleven respondents $(30 \%)$ were categorized as disagreeing with this proposition, with one strongly disagreeing (3\%) and the remaining 10 mostly disagreeing $(27 \%)$. Although these 10 individuals were categorized as disagreeing with the logical proposition, they acknowledged the importance of postharvest handling, but believed that other factors were more influential in successfully providing consumers with high-quality, flavorful fruit (Table 2).

THEMES RELATED TO AGREEMENT. The most frequent themes related to agreement with the proposition that fruit handling affects fruit flavor were gentle handling $(n=22)$, cold chain management $(n=21)$, and harvest timing $(n=20)$.

Gentle handling $(n=22)$. For respondents who identified gentle handling as an issue, their responses were further coded to indicate where in the supply chain they emphasized handling. When individuals mentioned multiple points in the supply chain, they received multiple codes. This analysis revealed that interviewees mentioned gentle handling throughout the supply chain $(n=12)$, during packing $(n=10)$, during shipping $(n=$ $6)$, during picking $(n=5)$, at retail ( $n=$ $3)$, and at the farm $(n=1)$.

One interviewee, a shipping and distribution expert, nicely described the importance of gentle handling throughout the supply chain for maintaining fruit flavor quality and preventing fruit

Table 1. Breakdown of the number of interview participants by the fruit industry segment they represent $(n=37)$.

Fruit industry segment represented Interview participants (no.)

Association/mandated marketing program 7

Retailer

Grower/packer/shipper 8

Other

18

Total 37

Table 2. Interview participants' level of agreement by fruit industry segment with logical proposition I: To what extent do industry decision makers agree with the proposition that better postharvest fruit handling is related to better fruit flavor? Level of agreement coded as strongly agree, mostly agree, mostly disagree, and strongly disagree $(n=37)$.

\begin{tabular}{lllllr}
\hline & \multicolumn{5}{c}{ Fruit industry segment } \\
\cline { 2 - 6 } Level of agreement & $\begin{array}{c}\text { Association } \\
(\boldsymbol{n}=\mathbf{7})\end{array}$ & $\begin{array}{l}\text { Retailer } \\
(\boldsymbol{n}=\mathbf{8})\end{array}$ & $\begin{array}{c}\mathbf{G P S}^{\mathbf{z}} \\
(\boldsymbol{n}=\mathbf{1 8})\end{array}$ & $\begin{array}{c}\text { Other } \\
(\boldsymbol{n}=\mathbf{4})\end{array}$ & $\begin{array}{c}\text { Total } \\
(\boldsymbol{n}=\mathbf{3 7})\end{array}$ \\
\hline Strongly agree & $3(43 \%)$ & $\mathbf{5}(63 \%)$ & $7(39 \%)$ & $3(75 \%)$ & $18(49 \%)$ \\
Mostly agree & $3(43 \%)$ & $0(0 \%)$ & $4(22 \%)$ & $1(25 \%)$ & $8(22 \%)$ \\
Mostly disagree & $0(0 \%)$ & $3(38 \%)$ & $7(39 \%)$ & $0(0 \%)$ & $10(27 \%)$ \\
Strongly disagree & $1(13 \%)$ & $0(0 \%)$ & $0(0 \%)$ & $0(0 \%)$ & $1(3 \%)$ \\
\hline
\end{tabular}

${ }^{{ }^{\mathrm{z}} \mathrm{GPS}}=$ Grower$/$ packer $/$ shipper. 
shrinkage (i.e., physical losses of fruit that must be discarded and, therefore, cannot be sold). This individual emphasized the importance of gentle handling for both "taste quality" and "loss" prevention:

For example, when fruit comes in out of the orchard, as it's picked from the tree, how are the pickers trained? Are they picking by the stem? Are they pulling and jerking? What's the pressure that they're using? Are they squeezing too hard? Once they get their buckets full and they empty them [pears] into the bins, are they dropping the fruit? Putting the fruit in gently? All causing bruising issues, one is a compression bruise and the other one is an impact bruise. And then, once it's in the bins and it's carried out of the orchard onto the flatbed truck, how is that delivery system being done? If somebody is running a forklift at high speeds going through ruts and whatever the fruit is being bounced in the bins. Likewise when the fruit is taken off the truck at the warehouse and moved into a storage room, the forklift drivers are in a burry and sometimes that fruit just bounces and bounces and bounces in the bins. Then, once fruit is taken from the storage room and run over to the packing facilitypeople sometimes just don't walk their lines, they just don't take a look at impact areas where fruit may be bouncing off of a corner that is unpadded or the padding is just worn away after continual use. . . It's a long process of looking at where this damage could actually come from so fruit that otherwise meets all the good qualities is bruised.

Prevention of loss is also a key point for retailers, with one interviewee discussing the successful gentle handling procedures used by a grower with an established reputation for producing flavorful fruit: "I think it's just about the care in which they handle the product. The way they pick products, they pick them into smallermore totes, if you will- than big bins. So when it comes to the packing shed, they don't dump them out, they are almost able to roll them out which keeps bruising down."

When discussing how to get riper, better-tasting fruit to consumers, another interviewee stressed the challenge of "understanding the unique handling and care that the product needs and then making sure that our supply chain can actually get it from point $A$ to point $B$, not only it looks good in the store, but also it maintains its freshness for a number of days, that we determine for our customers, once they get it to their homes."
One association representative spoke of the use of improved handling techniques to preserve fruit flavor quality by protecting the physical condition of the fruit: "Place-pack trays and things like that for pears and peaches, you know, you didn't see that 10 years ago. So, all of those kinds of handling remedies are going a long way towards improving the quality of the fruit when it actually reaches the marketplace." Another association representative stated that more improvements are needed to harvest riper, more flavorful fruit, "I think that there's a generally held belief that stuff is harvested too early so we can ship it. So, if we could improve the handling capabilities then we could deliver a better quality material."

Cold chain management $(n=21)$. Twenty-one participants stated that cold chain management was critical to delivering high-quality, flavorful fruit to consumers. For example, one association representative stated, "If, in fact, you can ensure good handling and temperature control on the product . . . because you're dealing with a biologically living product, you can deliver a better quality product." Participants discussed cold chain management at all stages of the supply chain with specific mentions being given to shipping $(n=15)$, throughout the supply chain $(n=9)$, at retail $(n=6)$, and during packing $(n=3)$.

Several interviewees mentioned the need to recognize and maintain the different storage temperature requirements of fruit to prevent damage, with most comments referring to chilling injury $(\mathrm{CI})$. An international grower of peaches stated, "One of the big problems with peaches is the cold chain. If they get in that spot of $45-55^{\circ} \mathrm{F}$ it kills the flavor-does the same with tomatoes. . . . Temperature always has a big effect on quality." An association member said, "There is a handling function, at least in tomatoes anyway, it certainly may be different with something like a strawberry or a blueberry where you've got some cold chain issues that you need maintained. With a tomato it's almost the opposite situation . . . you want to keep it out of the refrigeration."

Many interviewees mentioned that although the cold chain is susceptible to breakdown at any point, there is a greater incidence of breakdown at the retail level where fruit is not kept at the appropriate storage temperatures, possibly because retail produce workers lack the appropriate knowledge, stores do not have enough cold zones, or the stores use refrigeration as a means to prevent ripening. A national retailer discussed these challenges:

\footnotetext{
At the store level, refrigeration is all set the same on the sales floor so all the cases are usually set at $38^{\circ} \mathrm{F}$. Your back room cooler is set to $38-40^{\circ} \mathrm{F}-$ for everything. So we know now better that a lot of products will have chill damage to them if they're put on a $38^{\circ} \mathrm{F}$ refrigerated case or in a $38^{\circ} \mathrm{F}$ cooler environment. So we're beginning to study that more, and see if we can address it by separating temperature zones in our produce back room and changing our temperatures in our retail cases to reflect more of what the product temperature needs are.
}

An international grower/packer/ shipper of tomatoes said, "I've put a lot of our blame on supermarkets not handling the product the way they should and trying to judge their shrink . . . and if the market doesn't warrant a lot of demand, they'll hold the fruit back at colder temperatures to keep what tomatoes they have on hand instead of letting them continue to really ripen so people would be more apt to buy them." Storing tomatoes at below the recommended temperatures contributes to $\mathrm{CI}$ and inhibits the natural development of sugars (Beckles, 2012).

Harvest timing $(n=20)$. The third most frequent reason for agreement was harvest timing, with many interviewees emphasizing the need to harvest at the best time to ensure optimal flavor. One interviewee said, "If we can get the grower to harvest the fruit, the strawberry, the melons, at the right time, when they are fully mature, then we'll start seeing bettertasting melons all over the place." Although several respondents echoed the previous statement, several others emphasized that there was an essential conflict between the need to harvest fruit at optimum maturity and the need to harvest earlier to maximize shelf life and allow for sufficient time for the fruit to travel through the supply chain. One interviewee said, "As a grower/ shipper/importer, often we can't harvest at the optimal time, we have to harvest at optimal shelf life, so it is a compromise." 
Many industry experts who discussed harvesting at optimal maturity also mentioned the need for gentle handling and more rapid movement through the supply chain. One peach grower/packer/shipper said, "Here locally we can pick at a little bit of a riper stage, but again we are faced with all of the difficulties as far as bruising, softness, decay, and other sorts of rejections at the retail level if we try and pack the fruit any riper than it is. A lot of people don't realize how long it takes to get to the store after we pack it."

One of the primary challenges in postharvest handling is the tension between allowing fruit to mature or ripen on the plant to develop the best sugar balance while maintaining shipability. Although industry experts recognize that more mature or riper fruit are likely to taste better and be more popular with consumers, many industry representatives are cautious about working with more mature or riper fruit because of the inherent challenges of packing and shipping more delicate fruit through the supply chain. All segments of the supply chain are cautious about the shrinkage, or waste, that may be associated with allowing fruit to become more mature or riper before harvesting them: "From a quality/ taste standpoint you want it to be at maximum peak of taste and firmness and ripeness and that sort of thing, but the riper a product is the more likely it is to get bruised or break down early and so it's a very fine line where you harvest stuff and the point of letting it get full ripe."

Frequently, respondents discussed shelf life and harvest timing in the context of other factors such as variety and growing conditions. For example, one grower/packer/shipper of strawberries, blueberries, and melons said that "You can handle a strawberry or papaya extremely well but if it is not the right variety and if you didn't harvest it on time the excellent handling will not affect taste.”

THEMES RELA TED TO DISAGREEMENT. The most frequently mentioned themes related to disagreement were variety grown $(n=$ 17), shelf life $(n=8)$, and growing conditions such as weather and soil conditions $(n=8)$. In many cases, the reasons for disagreeing with the proposition that fruit handling affects fruit flavor were based on alternative considerations or other factors that affect fruit flavor and quality. In almost all cases, those who disagreed somewhat with this proposition acknowledged the importance of fruit handling, but believed other factors were equally if not more important.

Variety grown $(n=17)$. Many respondents discussed the role of fruit varieties in delivering flavorful fruit to consumers. In response to whether fruit handling affects fruit flavor, a grower/packer/shipper of tomatoes said, "I don't know, because the taste is determined by variety, remember that. The other pieces can hurt it, meaning your lack of using good technology, but ultimately it comes down to variety. What variety are you using? You can't take a bad tasting tomato and make it taste better." Similarly, a peach grower/packer/shipper illustrated the point, “It doesn't matter what you do-a poor variety is a poor variety and it needs to be replaced." Many respondents acknowledged the importance of both variety and postharvest handling, an opinion that was summarized by an association representative, who said, "I think it [postharvest handling] is part of the equation, I think good genetics are a piece of this as well ... I think it's got to be a 50/ 50 proposition. I really do ... so you not only have to handle it right in the supply chain, in the most effective way possible to both maintain the shipping quality and the taste experience for the piece of fruit, but you've got to have a good piece of fruit to begin with, otherwise, you've only addressed half the issue." In essence, industry experts recognize the need to integrate selection of varieties and good preharvest practices with good postharvest fruit handling - to deliver flavorful fruit, you must pay attention to both (Tijskens and van Kooten, 2006).

Shelf life $(n=8)$. As mentioned above, the concept of shelf life is intricately linked to harvest timing. In response to whether fruit handling affects flavor, a representative of a major international fruit grower said, "I have to be a little bit cynical or skeptical that there would be a difference in taste. Again, the best practices for handling are empirical . . . I don't see how they can be altered in favor of improving taste without having negative effects on, for example, shelf life." In discussing the challenges of maximizing shelf life, he said:
You're going to laugh, but I think it's the supply chain itself. It's the shipper who wants to make sure he can send his product from California to New York. It's the trucker who wants to be able to truck it and it lasts that long. And it's the retailer who gets it in his warehouse and turns it in a day and a half or two days to the supermarket who wants it to last that long. It's the consumer who takes it home on a Monday, but wants it to last throughout the week. I really think it's the whole supply chain.

Another respondent, a pear grower, connected the concept of shelf life to consumer demand, suggesting that:

\footnotetext{
If the demand was really high and we didn't have to keep them [pears] in cold storage. . you would want to keep them on the tree a little longer, get them out, and they [the consumer] could enjoy this perfect fruit. since it takes some time to move this fruit, we have to have them a little greener so we can hold them longer. So I think it's not just a matter of handling, it's a matter of demand. If we're selling out every single day then we could get that fruit a little riper, but we have to hold them, because we cannot move that quantity of fruit.
}

Growing conditions $(n=8)$. Respondents who highlighted growing conditions as a determinant of fruit flavor mentioned the importance of air temperature, rainfall, sunlight, freeze dates, and soil conditions as important factors in developing fruit flavor. Most of the respondents coupled these concepts with the importance of varieties, but also acknowledged that fruit handling matters as well. A major tomato grower said that fruit flavor quality was affected by "time of the year and soil conditions." A strawberry grower said, "We have great flavor just naturally December, January, and February. Then you hit March and get into some warm weather and maybe a few rains mixed in, and the flavor goes out."

A representative of a seed company illustrated the interrelatedness of the factors affecting fruit flavorthat producers must grow the correct variety for the given environmental conditions, must pick the fruit at the proper time, and must handle the fruit properly throughout the supply chain: "There are ideal conditions and less than ideal conditions, depending on the area and the time of year that growers are trying to produce product. And there can be, like I said, environmental variables that can affect quality 
such as day length, relative humidity, temperature variation night and day, things like that. There can also be external factors like disease pressure, insect pressure, and then again the other component would be genetics and that's where we fit in trying to find genetics that will perform well under even somewhat adverse conditions."

In summary, whether the themes were gentle handling, cold chain management, harvest timing, or preconditioning, $70 \%$ of respondents agreed that postharvest handling affects fruit flavor. And almost all the respondents who expressed disagreement with the proposition acknowledged the importance of postharvest handling, but felt other factors were important, mainly the variety grown, the shelf life requirements, and the growing conditions. Overall, industry experts recognized that delivering great-tasting fruit requires selecting appropriate varieties and farming practices as well as properly handling fruit throughout the supply chain.

\section{Logic II: Relationship between fruit flavor and increased consumption}

The second question in this study was to what extent is increased taste quality of fruit associated with increased purchasing and consumption? Interviewees were asked, "If the quality of fruit was increased significantly, how confident are you that consumers would purchase more of each kind of fruit?"

The respondents were overwhelmingly in agreement with the proposition that fruit consumption is driven by fruit flavor. Thirty-five of the 37 individuals (95\%) expressed agreement, with 28 strongly agreeing (76\%), and 7 mostly agreeing (19\%). The strength

Table 3. Interview participants' level of agreement by fruit industry segment with logical proposition II: To what extent do industry experts believe that better fruit flavor quality will lead to more consumer purchasing? Level of agreement coded as strongly agree, mostly agree, mostly disagree, and strongly disagree $(n=37)$.

\begin{tabular}{llllll}
\hline & \multicolumn{5}{c}{ Fruit industry segment } \\
\cline { 2 - 6 } Level of agreement & $\begin{array}{c}\text { Association } \\
(\boldsymbol{n}=\mathbf{7})\end{array}$ & $\begin{array}{c}\text { Retailer } \\
(\boldsymbol{n}=\mathbf{8})\end{array}$ & $\begin{array}{c}\text { GPS }^{\mathbf{z}} \\
(\boldsymbol{n}=\mathbf{1 8})\end{array}$ & $\begin{array}{c}\text { Other } \\
(\boldsymbol{n}=\mathbf{4})\end{array}$ & $\begin{array}{c}\text { Total } \\
(\boldsymbol{n}=\mathbf{3 7})\end{array}$ \\
\hline Strongly agree & $7(100 \%)$ & $7(88 \%)$ & $11(61 \%)$ & $3(75 \%)$ & $28(76 \%)$ \\
Mostly agree & $0(0 \%)$ & $1(13 \%)$ & $6(33 \%)$ & $0(0 \%)$ & $7(19 \%)$ \\
Mostly disagree & $0(0 \%)$ & $0(0 \%)$ & $1(6 \%)$ & $1(25 \%)$ & $2(5 \%)$ \\
Strongly disagree & $0(0 \%)$ & $0(0 \%)$ & $0(0 \%)$ & $0(0 \%)$ & $0(0 \%)$ \\
\hline
\end{tabular}

${ }^{\mathrm{z}} \mathrm{GPS}=$ Grower $/$ packer $/$ shipper.

of the agreement was noteworthy, with interviewees using strong language to express their agreement, including phrases such as "absolutely," "most definitely," "very confident," and " $100 \%$ confident" that fruit flavor quality affects consumer purchasing. The two individuals in disagreement were categorized as "mostly disagree" with one basing his reasoning on the idea that those who eat fruit want better-tasting fruit, but would not necessarily buy "more" fruit. He also stressed that an alternative strategy would be to build demand by using tasting demonstrations to induce people who currently do not purchase fruit to try, taste, and purchase fruit (Table 3 ).

As with the first logical proposition, grower/packer/shippers were relatively more cautious and more likely to offer alternative considerations when discussing the logical connection between fruit flavor quality and consumer purchasing, with 11 strongly agreeing (61\%) and 6 mostly agreeing (33\%).

TheMES RELATED TO AGREEMENT. When discussing their reasons for agreeing with the idea that better taste would equal increased consumption, the themes related to agreement were the connection between fruit taste and repeat buying $(n=28)$, agreement based on experience $(n=$ $7)$, and consistency of fruit flavor quality $(n=4)$.

Repeat buying $(n=28)$. By far, the most frequent reason for agreeing with the proposition that better fruit flavor would be associated with more consumer purchasing is the concept of repeat buying. For example, a representative of a peach association said, "If consumers have a satisfactory eating experience then they'll go back

Hortlechnology · October $201323(5)$ and buy more." Another representative of a major fruit packing company illustrated the point by saying, "We understand that the only way we are going to increase the demand on fruits is by delivering better quality to the consumer. There are very few things we can do different to increase the sales, but if we do only one thing which is improving the taste, the flavor, the quality of the product we deliver to the consumer, we know that the consumer likes that and will purchase it again." A representative of a blueberry association acknowledged regional differences in blueberry flavor quality and went on to say, "I think if we could pump out some really tasty berry we'd have a whole new world on our hands."

The idea that increased consumption leads to increased sales was mentioned by participants from all stages in the supply chain. A pear grower provided a vivid description, "You know it's like when you get that pear that is so juicy and sweet it's running down your chin and dripping off, you want another one." A retailer said, "If you come to [our store] and you get good tomatoes, get good peaches, blueberries, cantaloupes, you say, 'I am going to go back there' ... you will definitely increase your sales." A peach grower/packer/shipper said, "If you are willing to pay for a premium product and generate the return sales you are going to make more money-we are going to make more money and that's really the key right there." A representative of a major fruit packing and shipping firm also related the concept of repeat sales to contractual agreements with growers, saying, "If you give me good tasting melons and my customer is going to repeatedly purchase, I will increase the contracted volume with you." One retailer stated, "The onus is on really everybody in the supply chain," emphasizing that all segments of the supply chain must work together to deliver the best quality fruit. This individual also said, "If they can prepare the fruit and harvest it in a closeto-ripe, ready-to-eat stage, then we will increase our sales. If we increase our sales, then the orders to those suppliers will increase so their business grows and it's just a positive spiral upward."

Agreement based on experience $(n=7)$. The second most popular reason for expressing agreement with 
the proposition was that interviewees had witnessed or experienced the relationship between fruit flavor quality and consumer purchasing. For example, one grower/packer/shipper of strawberries and blueberries stated that he was "very confident" in this link and that "we have proof to show that." He went on to say that "When we have great tasting product whether it is strawberries or citrus or anything, you can see it easily because consumers buy more of it, they come back to the stores more frequently ... you can talk to any retailer and when peaches taste great they fly out the door."

In support of improving the consumer's eating experience, a retailer said, "Yes, I agree 1000\% [sic]" and went on to describe how his company selects growers based on their ability to provide flavorful fruit: "That is why we're working with players that are innovators, who are trying to seek out nursery stocks, hybrid items, cross-breeding items, ripping out old varieties and putting in new varieties because they eat better. And their whole mission in life is enhancing a customer's eating experience by providing a better item. If it starts potentially as a better item then it's up to a retailer and the distribution network to make sure it winds up in a customer's kitchen as it's supposed to be.”

Peach and pear growers typically related that their experience with preconditioning fruit (i.e., allowing partial ripening to occur postharvest before cooling and shipping) had convinced them that better-tasting fruit would be purchased more frequently. One peach grower said, "Well we did that with conditioning and we proved it. I guess we're living proof and we're confident of that because we've lived that. That's why we're in business now. We've had double-digit increases almost across the board once they switch to better-tasting fruit."

Consistency $(n=4)$. Some interviewees mentioned that consistency of fruit flavor was critical to consumer sales. A grower/packer/shipper of peaches said, "If we could get consistent and better, the sales would go through the roof. I am confident about that. But we can't seem to get there." A representative of a major national association illustrated the point further: "So I think if you can be more consistent-if you say something's going to taste good and you can deliver it to your store-even if you broke it into seasons and you say, 'Hey, in the summer months you've got this great stuff and you promote it, I think people would buy it every time they went to the store because you know the consistency is there and you're not going to get cheated. Until you get that consistency you're going to have this constant up and down." A representative of a tomato association agreed, saying, "I think if the consumer could consistently identify and get that taste of their preference there's no question their consumption levels would go up to some degree."

THEMES RE LA TE D TO DISAGREEMENT. Although most people agreed with the proposition that improving fruit flavor would lead to more consumer purchases, some respondents discussed other factors affecting consumer purchasing, including price $(n=10)$, retail display $(n=4)$, fruit appearance $(n=3)$, and product identity $(n=3)$.

Price $(n=10)$. The most frequently mentioned reason for disagreement, or alternative consideration, was price, with many interviewees recognizing the importance of both fruit flavor quality and fruit price and the need to balance these factors. For example, when asked whether he agreed that improved fruit flavor would lead to increased sales, one association representative expressed strong agreement, saying, "Well, absolutely, it's a demand issue for not only riper fruit, but for better-tasting and eating fruit. We've heard that on tomatoes for decades. It applies on all these commodities, if you have a riper piece of fruit at retail that they can get home and consume and enjoy, the demand will certainly be there." He then went on to explain that price is an important consideration as well: "There's a price point issue here certainly, but the demand-all things being equal-the demand is absolutely going to be there. I don't think there's any question about that." A grower/packer/ shipper of tomatoes and peaches also agreed with the proposition, saying "As long as the price point is sensible ... certainly if you can enhance any quality characteristic of the product you should develop more interest, which leads to more consumption." Finally, one interviewee, a pear grower, expressed the opinion that price, not flavor is the primary factor for consumers: "I don't know that just a little better quality product is going to be enough to move more fruit. I think that honestly, in this economy, a cheaper product would move more fruit."

Retail display $(n=4)$. Four respondents mentioned the importance retail displays play in capturing consumer attention in a highly competitive market, with one saying, "So you have to have the support of a retailer to display in size and location your product ... that commodity is counting on visual impact when you walk into the store." A peach grower linked retail display to product identity, saying, "The trick has been differentiating PLU (price look-up) numbers in the market place ... And then the next challenge after you've got them (PLU numbers) is to provide shelf space for them."

Product identity $(n=3)$. Establishing product identity was mentioned as a way to encourage repeat purchasing by branding great-tasting fruit with a recognizable label. A representative of a major grower/ packer/shipper strongly agreed with the proposition that consumers purchase based on flavor, but added that "better taste by itself will not equal more purchasing, but better taste along with some tag, some way of identifying that 'This is what I bought last time.' It has to be branded or somehow marked so that you know what to buy the second time."

Fruit appearance $(n=3)$. The three respondents citing appearance as a qualifier discussed their uncertainty that better handling would mean better-tasting fruit, but rather that improved fruit handling would increase consumption by preserving the appearance of the fruit. They framed the issue of appearance as a consumer misperception or education issue (or a consumer disconnect between the way a fruit looks and how it tastes). One grower/packer/shipper of pears said, "You want this absolutely perfect appearing piece of fruit but it's not necessarily the best tasting." Another said, "There again, if it looked a little better they might buy a little more. I don't know if the taste would change one way or the other ... I mean you can have an ugly piece of fruit that tastes good and you can have a big piece of fruit that's hard and doesn't taste good and it seems that that's the one that they will buy all the time." 
In summary, respondents from all industry roles expressed overwhelming agreement with the idea that increased flavor quality of fruit would mean increased purchasing and consumption. For the majority, the fact that better-tasting fruit would lead to repeat buying was the main reason for agreement. Having witnessed increased consumer consumption as a result of offering better-tasting fruit and the need for fruit to be consistently better tasting were other reasons for agreement. The one respondent who disagreed felt that current fruit eaters want better-tasting fruit, but would not necessarily purchase more fruit because it tasted better. Instead, he felt that better-tasting fruit could increase consumption by attracting new fruit eaters. Other factors thought to affect consumer purchasing were the price point of fruit, retail display, product identity, and fruit appearance.

\section{Conclusion}

Representatives across all segments of the fruit industry expressed broad agreement for the propositions that fruit handling affects fruit quality and flavor and that consumers would purchase more fruit if the quality were consistent. However, from a business perspective, it is a complex and challenging task to deliver optimally ripe, high-quality, flavorful fruit to consumers with minimal damage and sufficient shelf life. Current business pressures have encouraged all segments of the fruit industry to emphasize shelf life and shipability over fruit quality and flavor. With increasing consumer attention to fruit quality and a generally accepted belief that fruit flavor and quality drives consumer demand through repeat purchasing, there is an opportunity to shift industry practices toward postharvest handling that is conducive to good fruit flavor.

Given the scarcity of current social science research on issues related to postharvest fruit handling, the current study provides a foundation for understanding the ways in which industry experts discuss fruit handling, fruit flavor quality, and consumer purchasing. Through qualitative analysis and the use of direct quotes, it is possible to combine individual responses into larger categories and themes. This approach maintains the integrity of the natural language of the interviewees while allowing the researcher to generate a manageable framework for understanding the issues emerging from these conversations.

This study is based on a relatively small sample of fruit industry representatives. The respondents were not randomly selected from a larger population and are not representative of all industry experts in the United States. Many of the individuals who participated in these interviews were project stakeholders and may be more receptive to the propositions of this project than are those individuals who did not participate. In general, the sample consisted of relatively large operations and did not include many smaller producers and retailers whose business models may be focused on establishing niche markets that emphasize flavor and quality. All of these limitations make us somewhat cautious about the conclusions being drawn in this study and suggest that future work should include large-scale survey work with all industry segments.

Within the current project, ongoing scientific studies and trials are addressing many of the challenges inherent in delivering better-tasting fruit to consumers. This research includes the development and evaluation of the following: more rapid methods for measuring important flavor characteristics, including aroma volatiles, specific sugars, and organic acids; methods to nondestructively detect and sort fruit for harvest maturity; methods to slow fruit ripening after harvest [e.g., SmartFresh ${ }^{\mathrm{TM}}$ (AgroFresh, Spring House, PA) and MA packaging]; and improved packaging for shipping of ripe fruit. Each method offers an additional tool that can be used by the produce industry to harvest, handle, and safely deliver high-quality, better-tasting fruit to consumers.

Future research should include additional testing of combinations of tools leading to full integration of successful postharvest handling practices throughout the supply chain. In addition, feasibility studies and analyses of return on investment will assist the industry in translating this research into practice. Consumer-oriented research should focus on ways to communicate to consumers that fruit is of exceptional quality and flavor. Finally, surveys targeting larger numbers of industry representatives from all segments of the supply chain allowing for stronger and more sophisticated quantitative analysis would increase our understanding of the differences between groups and the relationships between key variables.

\section{Literature cited}

Beckles, D.M. 2012. Factors affecting the postharvest soluble solids and sugar content of tomato (Solanum lycopersicum L.) fruit. Postharvest Biol. Technol. 63:129140 .

Brecht, J.K., K.V. Chau, S.C. Fonseca, F.A.R. Oliveira, F.M. Silva, M.C.N. Nunes, and R.J. Bender. 2003. Maintaining optimal atmosphere conditions for fruits and vegetables throughout the postharvest handling chain. Postharvest Biol. Technol. 27:87-101.

Cantwell, M., X. Nie, and G. Hong. 2009. Impact of storage conditions on grape tomato quality. 5 June 2013 . <http://ucce.ucdavis.edu/files/datastore/ 234-1531.pdf>.

Centers for Disease Control and Prevention. 2010. State-specific trends in fruit and vegetable consumption among adults-United States, 2000-2009. Morb. Mortal. Wkly. Rpt. 59:1125-1130.

Forney, C.F. 2001. Horticultural and other factors affecting aroma volatile composition of small fruit. HortTechnology 11:529-538.

Kader, A.A. 2000. Quality of horticultural products. Acta Hort. 517:17-18.

Kader, A.A. 2001. Quality assurance of harvested horticultural perishables. Acta Hort. 553:51-56.

Kader, A.A. 2008. Flavor quality of fruits and vegetables. J. Sci. Food Agr. 88: 1863-1868.

Kimmons, J., C. Gillespie, J. Seymour, M. Serdula, and H.M. Blanck. 2009. Fruit and vegetable intake among adolescents and adults in the United States: Percentage meeting individualized recommendations. Medscape J. Medicine 11:26.

Mitcham, E.J. 2010. Focus on consumers to increase sales, p.28. In: American/ Western Fruit Grower. June 2010. University of California, Davis, CA.

Post, R.C., J. Haven, and S. Maniscalco. 2011. Setting the table with a healthy plate: Make half your plate fruits and vegetables. J. Amer. Dietetic Assn. 111: 1644-1647.

Thomas, D.R. 2006. A general inductive approach for analyzing qualitative evaluation data. Amer. J. Eval. 27:237246. 


\section{Preliminary and Regional Reports}

Tijskens, L.M.M. and O. van Kooten. 2006. Theoretical considerations on generic modelling of harvest maturity, enzyme status and quality behaviour. Intl. J. Postharvest Technol. Innovation 1:106-120.

Tijskens, L.M.M., P.E. Zerbini, R.E. Schouten, M. Vanoli, S. Jacob, M. Grassi,
R. Cubeddu, L. Spinelli, and A. Torricelli. 2007. Assessing harvest maturity in nectarines. Postharvest Biol. Technol. 45: 204-213.

Toivonen, P.M.A. 2007. Fruit maturation and ripening and their relationship to quality. Stewart Postharvest Rev. 3:1-5.
Zerbini, P.E. 2008. Managing maturity and ripening in the fruit production chain for improved flavour. Acta Hort. 804:6370 . 